\title{
DYNAMIC STABILITY TESTING OF THE GENESIS SAMPLE RETURN CAPSULE
}

F. McNeil Cheatwood

NASA Langley Research Center, Hampton, Virginia

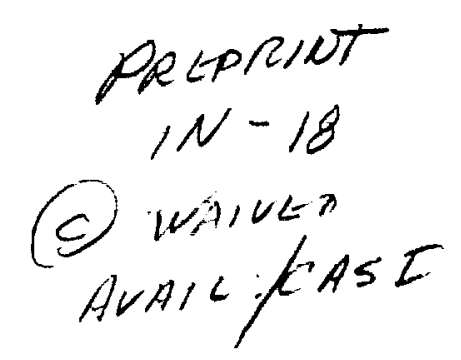

Gerald L. Winchenbach

Air Force Research Laboratory, Eglin AFB, Florida

Wayne Hathaway

Arrow Tech Associates, South Burlington, Vermont

Gary Chapman

Aerospace Computing, Inc., Los Altos, California

AIAA Paper No. 2000-1009

Presented at the 38th AIAA Aerospace Sciences Meeting and Exhibit

Reno, Nevada

January 10-13, 2000 


\title{
DYNAMIC STABILITY TESTING OF THE GENESIS SAMPLE RETURN CAPSULE
}

\author{
F. McNeil Cheatwood, ${ }^{*}$ NASA Langley Research Center, Hampton, VA \\ Gerald L. Winchenbach, ${ }^{\dagger}$ Air Force Research Laboratory, Eglin AFB, FL \\ Wayne Hathaway, ${ }^{\ddagger}$ Arrow Tech Associates, So. Burlington, VT \\ Gary Chapman, $\$$ Aerospace Computing, Inc., Los Altos, CA
}

\begin{abstract}
This paper documents a series of free flight tests of a scale model of the Genesis Sample Return Capsule. These tests were conducted in the Aeroballistic Research Facility (ARF), located at Eglin AFB, FL, during April 1999 and were sponsored by NASA Langley Research Center. Because these blunt atmospheric entry shapes tend to experience small angle of attack dynamic instabilities (frequently leading to limit cycle motions), the primary purpose of the present tests was to determine the dynamic stability characteristics of the Genesis configuration. The tests were conducted over a Mach number range of 1.0 to 4.5 . The results for this configuration indicate that the models were dynamically unstable at low angles of attack for all Mach numbers tested. At Mach numbers below 2.5, the models were also unstable at the higher angles of attack (above $15 \mathrm{deg}$ ), and motion amplitudes of up to $40 \mathrm{deg}$ were experienced. Above Mach 2.5, the models were dynamically stable at the higher angles of attack.
\end{abstract}

\section{Nomenclature}

$\begin{array}{ll}A & \text { reference area, } \pi \mathrm{D}^{2} / 4\left[\mathrm{~mm}^{2}\right] \\ \mathrm{C}_{\mathrm{D}} & \text { drag coefficient } \\ \mathrm{C}_{\mathrm{L}} & \text { lift coefficient } \\ \mathrm{C}_{\mathrm{m}} & \text { pitching moment coefficient } \\ \mathrm{C}_{\mathrm{m}_{\mathrm{q}}} & \text { damping-in-pitch derivative, }\left(\mathrm{C}_{\mathrm{m}_{\overline{\mathrm{q}}}}+\mathrm{C}_{\mathrm{m}_{\dot{\alpha}}}\right) \\ \mathrm{C}_{\mathrm{N}} & \text { normal force coefficient } \\ \mathrm{C}_{\mathrm{A}} & \text { axial force coefficient } \\ \mathrm{D} & \text { model diameter (reference length) }[\mathrm{mm}] \\ \mathrm{I}_{\mathrm{xx}}, \mathrm{I}_{\mathrm{yy}} & \text { moments of inertia about the x and y } \\ \mathrm{L} & \text { axes, respectively }\left[\mathrm{kg}-\mathrm{m}^{2}\right] \\ \mathrm{m} & \text { model length [mm] } \\ \mathrm{t} & \text { model mass [gm] } \\ & \text { time [s] }\end{array}$

* Aerospace Engineer, Vehicle Analysis Branch, Senior Member AIAA.

$\dagger$ Senior Scientist, Associate Fellow AIAA.

$\ddagger$ Vice President of Engineering, Senior Member AIAA.

$\S$ Consultant, Associate Fellow AIAA.

This paper is declared a work of the U.S. Government and is not subject to copyright protection in the United States.

\begin{tabular}{|c|c|}
\hline $\mathrm{V}$ & model velocity $[\mathrm{m} / \mathrm{s}]$ \\
\hline $\mathrm{x}, \mathrm{y}, \mathrm{z}$ & $\begin{array}{l}\text { coordinates of downrange, crossrange, and } \\
\text { vertical position, respectively }[\mathrm{m}]\end{array}$ \\
\hline $\mathrm{X}_{\mathrm{cg}}$ & $\begin{array}{l}\text { distance from model nose to center-of- } \\
\text { gravity }[\mathrm{mm}]\end{array}$ \\
\hline$\alpha$ & angle of attack [deg] \\
\hline$\alpha_{\text {limit }}$ & limit cycle amplitude [deg] \\
\hline$\alpha_{\text {otal }}$ & total angle-of-attack [deg] \\
\hline & roll angle [deg] \\
\hline$\Psi$ & fixed plane Euler angles [deg] \\
\hline
\end{tabular}

Subscript

$\alpha \quad$ derivative with respect to $\alpha$

\section{Introduction}

The fifth of NASA's Discovery class missions is a sample return mission known as Genesis. The spacecraft will be inserted into a halo orbit about the L1 libration point, between the Earth and the Sun, where it will remain for two years collecting solar wind particles. Genesis is scheduled to be launched in January of 2001, and will be the first mission to return samples from beyond the Earth-Moon system. Upon Earth return in August 2003, the sample return capsule (SRC) containing the solar wind samples will be released from the main spacecraft (decelerating with the aid of a parachute) for a mid-air recovery in Utah over the United States Air Force (USAF) Utah Test and Training Range (UTTR). A sketch of the spacecraft and capsule is shown in Figure 1.

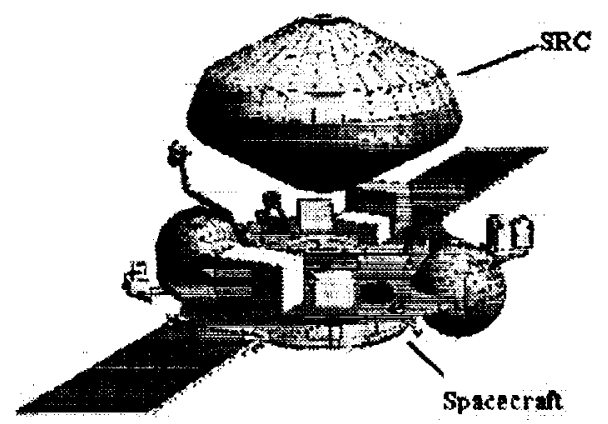

Figure 1. Genesis Spacecraft and Sample Return Capsule. 
The concerns with the dynamic stability of this configuration are associated with the angular motion of the SRC in supersonic flight, where the parachute is deployed, since large attitude excursions could prevent a successful deployment. This paper presents estimates of the dynamic stability characteristics, along with the static aerodynamic coefficients, extracted from trajectory data collected during free flight tests of scaled models of the Genesis SRC.

\section{Aerodynamic Testing}

\section{Aeroballistic Research Facility}

The tests were conducted in the USAF Aeroballistic Research Facility (ARF) that is illustrated in Figure 2. The Flight Vehicles Integration Branch (MNAV) of the Air Force Research Laboratory (AFRL) maintains and operates the ARF. The aerodynamic and stability characteristics of a test item are determined from the measurement of the test item's spatial and angular orientations observed during free flight in this facility.

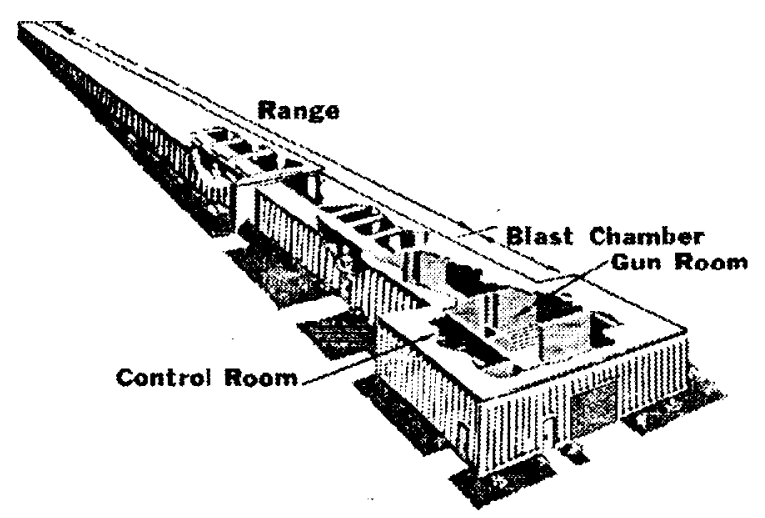

Figure 2. Aeroballistic Research Facility.

The ARF is an enclosed concrete structure. The facility is used to examine the exterior ballistics of various free-flight configurations. The facility consists of a gun room, control room, model measurement room, blast chamber, and an instrumented range. The 207meter range has a 3.66-meter square cross-section for the first 69-meters and a 4.88-meter square crosssection for the remaining length. Cameras at 50 stations along the length of the range provide orthogonal photographs of the model's shadow as it passes. These images provide the spatial position and angular orientation history of the test model for each shot. These discrete times, positions, and orientations are then used within the data reduction program to determine the aerodynamic forces and moments acting on the model during the observed flight.

\section{Models and Test Conditions}

The body of the models was milled from steel. A brass base plug was used to shift the model's center of gravity to about the $\mathrm{X}_{\mathrm{cg}} / \mathrm{D}=0.343$ location (see Figure 3 ). Since these blunt entry configurations have high drag characteristics, the models were designed to be relatively massive in order to minimize the deceleration experienced during flight in the test facility.

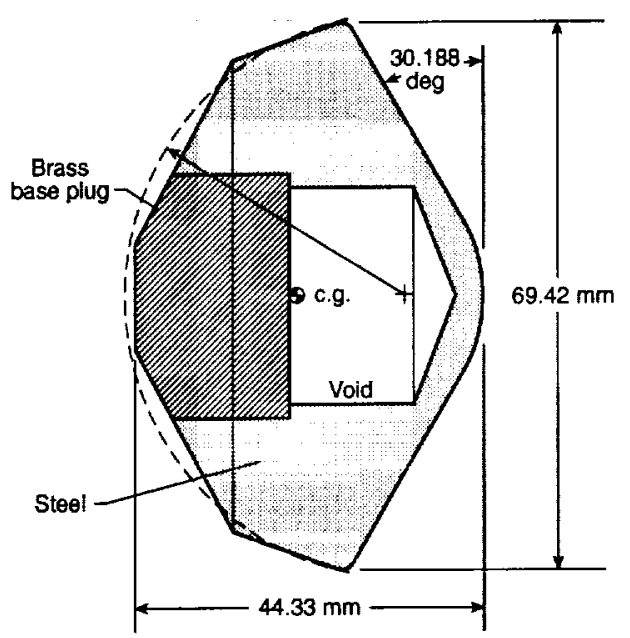

Figure 3. Sketch of the Sub-scale SRC Model.

Twelve 0.047 scale models (cradled in four-pedal sabots) were fired from a 76-mm smooth-bore singlestage powder gun. The nominal physical properties of the test models are given in Table 1 . The test program was conducted in controlled atmospheric conditions of approximately $21 \mathrm{deg} C$ and 55 percent relative humidity. Barometric pressures were approximately 1020 mbar. Table 2 summarizes the duration in distance of each test flights, as well as the measured atmospheric conditions in the facility during the tests.

Table 1. Physical Properties of the Genesis SRC Scale Models

\begin{tabular}{cc}
\hline \hline Parameter & Value \\
\hline $\mathrm{D}[\mathrm{mm}]$ & 69.42 \\
$\mathrm{~m}[\mathrm{gm}]$ & 633 \\
$\mathrm{I}_{\mathrm{xx}}\left[\mathrm{kg}-\mathrm{m}^{2}\right]$ & $3.01 \times 10^{-4}$ \\
$\mathrm{I}_{\mathrm{yy}}\left[\mathrm{kg}-\mathrm{m}^{2}\right]$ & $1.99 \times 10^{-4}$ \\
$\mathrm{~L}[\mathrm{~mm}]$ & 44.33 \\
$\mathrm{X}_{\mathrm{cg}}[\mathrm{mm}]$ & 23.83 \\
$\mathrm{X}_{\mathrm{ca}} / \mathrm{D}$ & 0.343 \\
\hline \hline
\end{tabular}

Initial muzzle velocities ranged from about $650 \mathrm{~m} / \mathrm{s}$ to $1600 \mathrm{~m} / \mathrm{s}$, yielding mid-range Mach numbers of about 1.4 to 3.5 , respectively. For some of the shots, the 
Table 2. Test Conditions

\begin{tabular}{cccccccc}
\hline \hline $\begin{array}{c}\text { Shot } \\
\text { Number }\end{array}$ & $\begin{array}{c}\text { No. of } \\
\text { Stations }\end{array}$ & $\begin{array}{c}\text { Observed } \\
\text { Distance } \\
{[\mathrm{m}]}\end{array}$ & $\begin{array}{c}\text { Pressure } \\
{[\mathrm{mbar}]}\end{array}$ & $\begin{array}{c}\text { Temperature } \\
{[\text { deg C }]}\end{array}$ & $\begin{array}{c}\text { Relative } \\
\text { Humidity } \\
{[\%]}\end{array}$ & $\begin{array}{c}\text { Density } \\
{\left[\mathrm{kg} / \mathrm{m}^{3}\right]}\end{array}$ & $\begin{array}{c}\text { Speed of } \\
\text { Sound } \\
{[\mathrm{m} / \mathrm{s}]}\end{array}$ \\
\hline R990407 & 31 & 137.2 & 1019.98 & 19.79 & 56.0 & 1.2130 & 343.11 \\
R990406 & 42 & 181.4 & 1019.98 & 19.79 & 56.0 & 1.2130 & 343.11 \\
R990495 & 45 & 199.7 & 1021.68 & 20.21 & 55.0 & 1.2133 & 343.36 \\
R990403 & 37 & 175.4 & 1019.98 & 19.79 & 56.0 & 1.2130 & 343.11 \\
R990496 & 48 & 199.7 & 1022.01 & 20.21 & 54.0 & 1.2136 & 343.36 \\
R990405 & 28 & 112.8 & 1019.98 & 19.79 & 56.0 & 1.2130 & 343.11 \\
R990497 & 46 & 199.7 & 1014.56 & 19.66 & 55.0 & 1.2071 & 343.04 \\
R990498 & 46 & 199.7 & 1006.44 & 19.66 & 60.0 & 1.1974 & 343.04 \\
R990499 & 41 & 198.1 & 1018.97 & 19.66 & 54.0 & 1.2123 & 343.04 \\
R990404 & 37 & 180.3 & 1019.98 & 19.79 & 56.0 & 1.2130 & 343.11 \\
R990401 & 27 & 141.7 & 1021.34 & 19.72 & 56.0 & 1.2149 & 343.08 \\
R990402 & 26 & 111.3 & 1019.98 & 19.79 & 56.0 & 1.2130 & 343.11 \\
\hline \hline
\end{tabular}

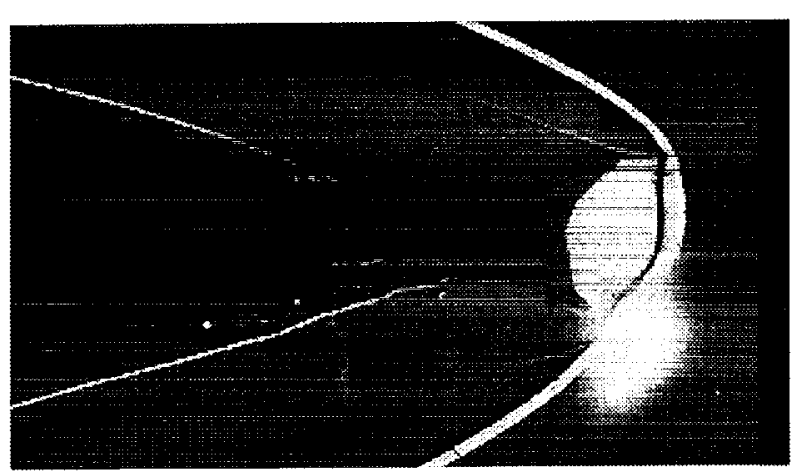

a. Station 02 (hall camera), Shot 990401.

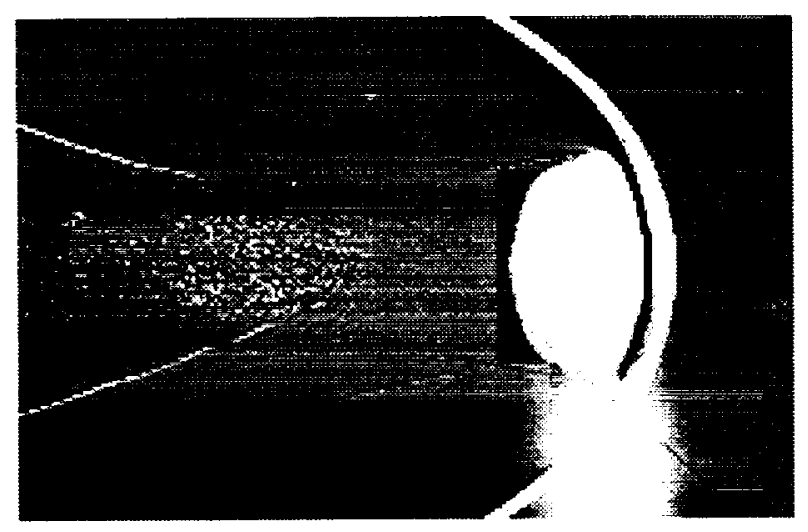

b. Station 02 (pit camera), Shot 990405.

Figure 4. Typical In-flight Shadowgraphs Aerodynamic Parameter Identification.

models were perturbed as they exited the blast chamber to introduce a non-zero angle of attack and foster growth in oscillations. Figure 4 contains typical shad- owgraph images showing the test configuration in flight for two of the twelve flight tests. Note that roll orientation and spin rates were not measured during the current tests. Prior testing of similar blunt entry configurations determined that the associated roll rates could be assumed to be small.

\section{Aerodynamic Parameter Identification}

The procedure for the trajectory analysis of data collected in a given free-flight experiment involves:

1. film reading to determine orientation of the test model with respect to the range reference system,

2. reconstructing the experimental trajectory via a six degree-of-freedom (6-DoF) simulation to match the vehicle orientation at each timing station,

3. mathematically modeling the test configuration's theoretical equations of motion, and

4. matching these theoretical equations to the experimental data in order to determine the aerodynamic parameters of the test item.

This complete process is described in Reference 2 .

The film reading and trajectory calculations are performed using the Comprehensive Automated Data Reduction and Analysis System, (CADRA). ${ }^{3}$ The trajectory matching process (diagrammed in Figure 5) is accomplished using the Aeroballistic Research Facility Data Analysis System, (ARFDAS), ${ }^{4}$ see Figure 5. The final product of this effort is a set of aerodynamic force and moment coefficients which describes the experimentally measured motions.

ARFDAS incorporates a standard linear theory analysis ${ }^{5,6}$ and a $6-\mathrm{DoF}$ numerical integration technique. The 6-DoF routine incorporates the Maximum Likelihood Method (MLM) to match the theoretical trajectory to the experimentally measured trajectory. The 


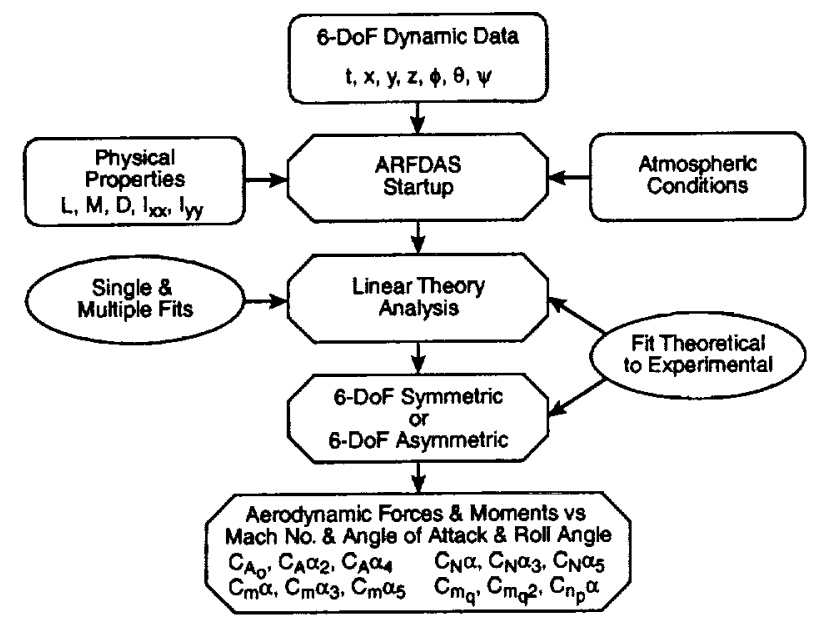

Figure 5. ARFDAS Parameter Identification Process.

MLM is an iterative procedure that adjusts the aerodynamic coefficients to maximize a likelihood function. The use of this likelihood function eliminates the inherent assumption in least squares theory that the magnitude of the measurement noise must be consistent between dynamic parameters (irrespective of units). In general, the aerodynamics can be nonlinear functions of the angle of attack, Mach number, and aerodynamic roll angle.

Each of the twelve shots was initially analyzed separately, then sectionally analyzed by stepping through each experimental trajectory, and finally, combined in appropriate groups for simultaneous analysis using a multiple fit approach. The multiple fit technique provides a common set of aerodynamics that match each of the separately measured position-attitude-time profiles, and provides a more complete spectrum of angular and translational motion than would be available from a single trajectory considered separately. This increases the probability that the resultant coefficients define the model's aerodynamics over the entire range of test conditions.

\section{Aerodynamic Results}

Aerodynamic force and moment coefficients have been extracted from each set of free flight motion data from the ARF. The methodology includes 6-DoF matching of the observed motions to determine the aerodynamics. The free flight trajectory data has been analyzed using numerous iterations for all of the flights. The primary objective has been to achieve the best match to the experimentally measured trajectory measurements and thereby extract the best estimates of the aerodynamics of the vehicle. The process also provides an indication as to the accuracy of the aerodynamics through direct comparison with the measurements.

The axial force coefficients determined from the flight data are contained in Figure 6 for $\alpha_{\text {total }}=0$ deg. The shaded symbols in this figure (as well as subsequent figures) correspond to the results of matching multiple flight trajectories to a common set of aerodynamics. Figure 7 shows the variability of the axial force with angle of attack. As expected, the axial force coefficient tends to decrease with increasing angle of attack.

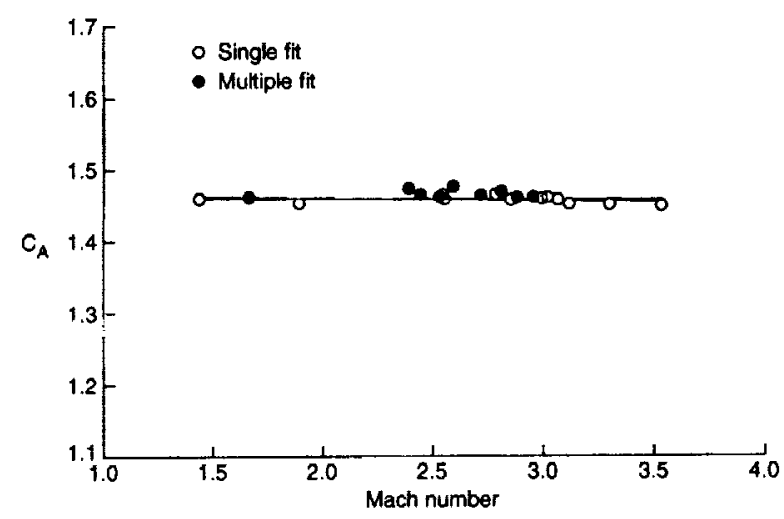

Figure 6. Axial Force Coefficient vs. Mach Number at $\alpha_{\text {toxal }}=0$.

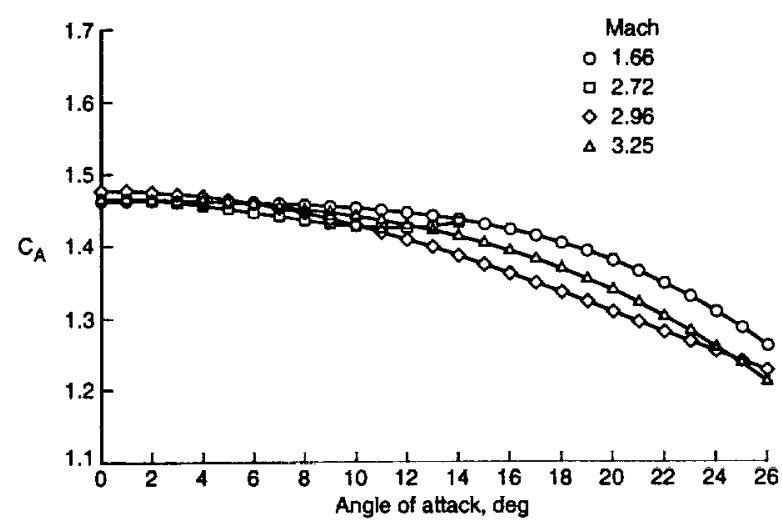

Figure 7. Axial Force Coefficient vs. Angle of Attack.

Figure 8 presents the results for the derivative of the normal force coefficient. For these blunt configurations, the normal force coefficient is perhaps the most difficult to measure. The heavy models employed in these tests to minimize velocity decay during the free flight through the facility exacerbate the problem. Based on Figure 8, the derivative of the normal force coefficient is approximately 0.15 .

Figure 9 shows the derivative of the pitching moment coefficient as a function of Mach number. The 


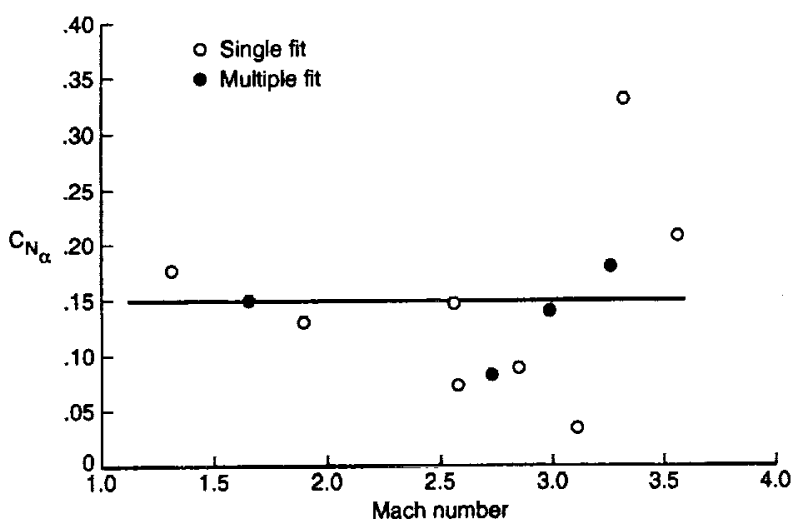

Figure 8. Normal Force Coefficient Derivatives vs. Mach Number.

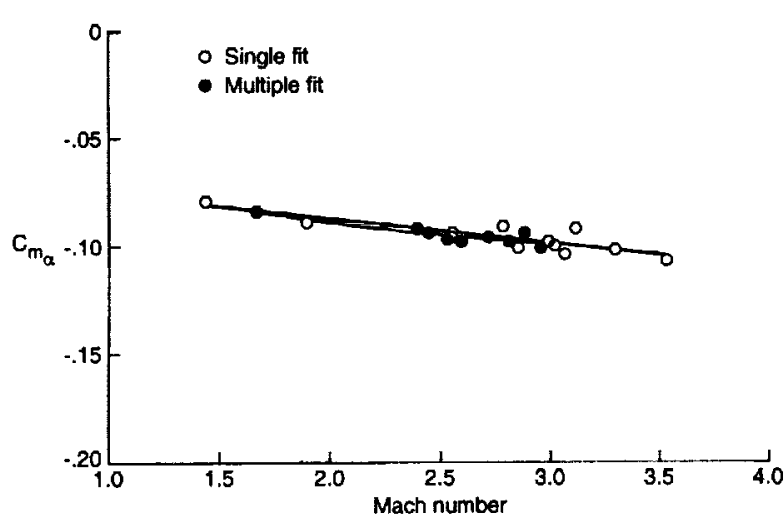

Figure 9. Pitching Moment Coefficient Derivative vs. Mach Number.

analysis indicated that no significant nonlinearities were present in the pitching moment data.

Figure 10 shows the pitch damping moment versus angle of attack. The default aerodynamic model within ARFDAS could not accurately model the nonlinearity of the behavior. Using the sliding sectional fit option in ARFDAS, the pitch damping was extracted over smaller sections of the measured trajectories. The results of the sectional fits provided the general form of the $\mathrm{C}_{\mathrm{mq}}$ function. The coefficients for this expression were determined through a best fit of the trajectories for the various Mach number regimes. Based on changes to the ARFDAS aerodynamic model, the $\mathrm{C}_{\mathrm{m} q}$ curves obtained from the form-factored fits, improved model, are shown in Figure 10, along with the sectional fit results.

The dynamic stability limit for this model was computed using the linear theory relationship, and was found to be approximately -0.175 . It varies only slightly with Mach number and angle of attack. Thus, for $\mathrm{C}_{\mathrm{mq}}<-0.175$, the model's angular motion should damp, while for $C_{m q}>-0.175$, the motion should grow. Based on this limit, Figure 10 indicates that the models are highly dynamically unstable at the lower angles of attack, possibly stable between 8 and 15 degrees, and then unstable again at higher angles of attack (for Mach numbers below 2.5). It appears that above Mach 2.5, the models remain dynamically stable at the higher angles of attack.

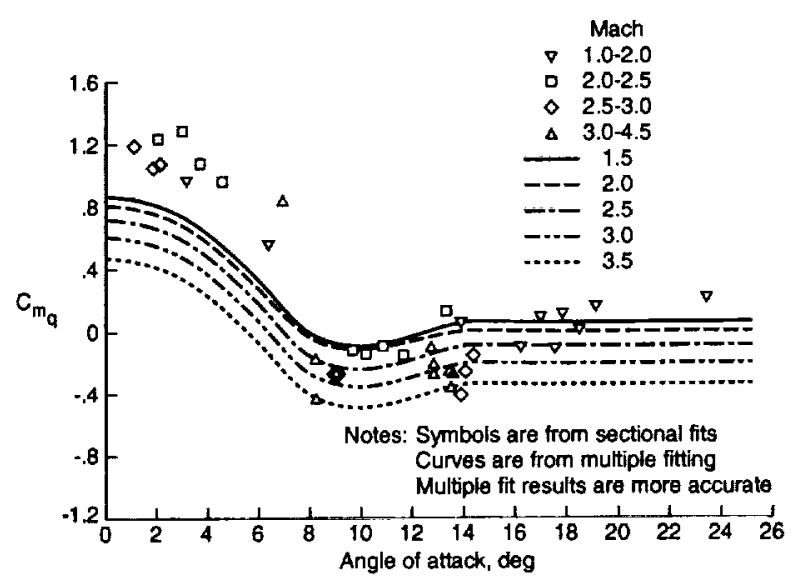

Figure 10. Pitch Damping Moment Coefficient vs. Mach Number.

\section{Motion Characteristics}

The angular motions resulting from the free-flight tests of the Genesis SRC are illustrated in Figure 11. In this figure, the total angle of attack $\left(\alpha_{\text {tocal }}\right)$ is plotted versus distance flown. Initial amplitudes for the shots varied from a low of approximately 0 deg to nearly 20 deg. As mentioned previously, the high initial amplitudes were obtained by exciting the motion as the model entered the instrumented portion of the test facility.

The sub-scale models of the Genesis SRC are dynamically unstable for small $\alpha_{\text {total. }}$. The motion growth trends are very consistent. However, the rate at which the motion grows is a function of Mach number. Note the difference in damping trends between the lower Mach numbers (Figures $11 \mathrm{a}$ and $1 \mathrm{lb}$ ), which are at 35 deg angle of attack and still growing rapidly, and the higher Mach numbers (Figures $11 \mathrm{k}$ and 111 ), whose amplitudes are not significantly increasing. This is consistent with the motions shown in Figures $11 \mathrm{c}$ to $1 \mathrm{lh}$ (and their progressively increasing Mach numbers), where the rate at which the motion grows appears to be decreasing.

It is suspected that the two flights at the highest Mach numbers may not be approaching a limit cycle in the classical sense. Instead they appear to approach a 
level approximately equal to the amplitude at the beginning of the shot. Nevertheless, the dynamic instability is significantly greater at the lower Mach number conditions and for those conditions no measurable limit cycle is apparent below $40 \mathrm{deg}$.

It has been previously shown ${ }^{8.9}$ that hemispherical bases with their center of radius located at the model's center of gravity eliminate the low angle of attack dy-

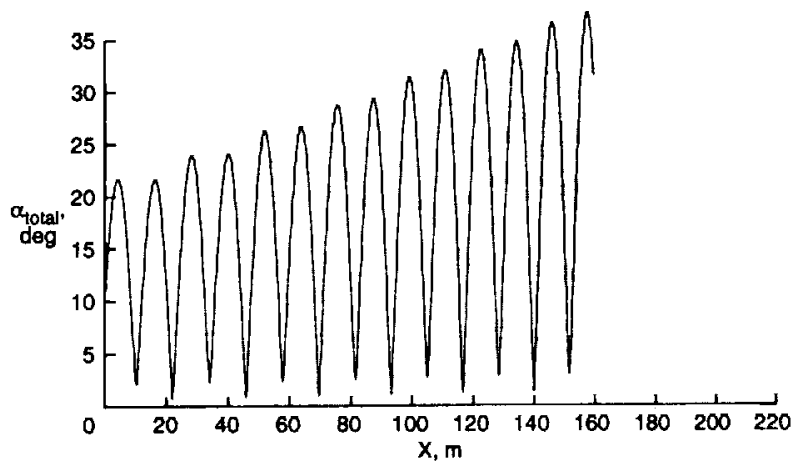

a. Mach 1.4 Average $(M=1.88$ to 0.99$)$.

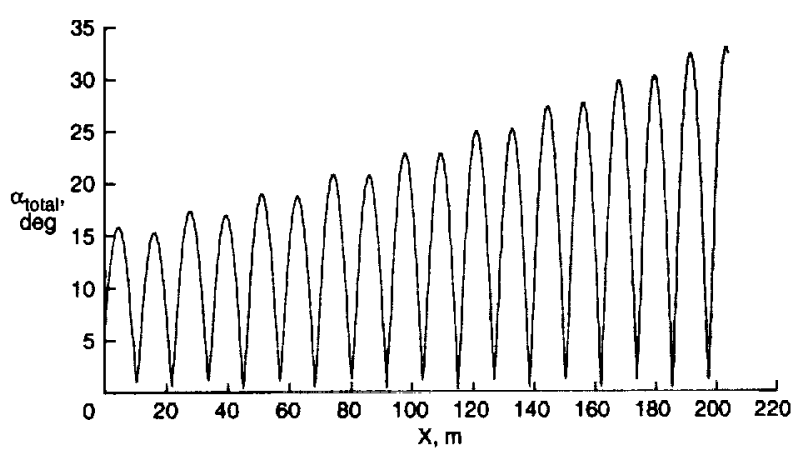

b. Mach 1.9 Average $(M=2.68$ to 1.10$)$.

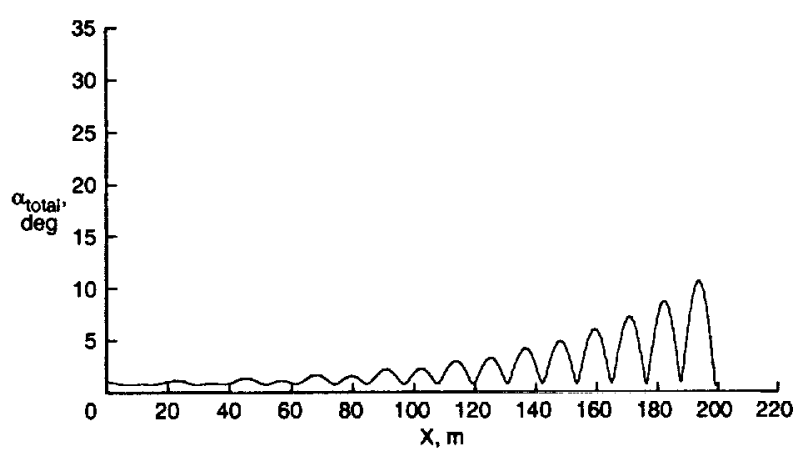

c. Mach 2.5 Average $(M=3.65$ to 1.44$)$. namic instability. As shown in Figure 3, the base of the Genesis SRC approximates a hemisphere. However, the center for this effective hemispherical radius is forward of the vehicle center of gravity. It is believed that the forward location of the center of this effective radius has contributed significantly to the dynamic instability of the Genesis SRC, as demonstrated by the present data.

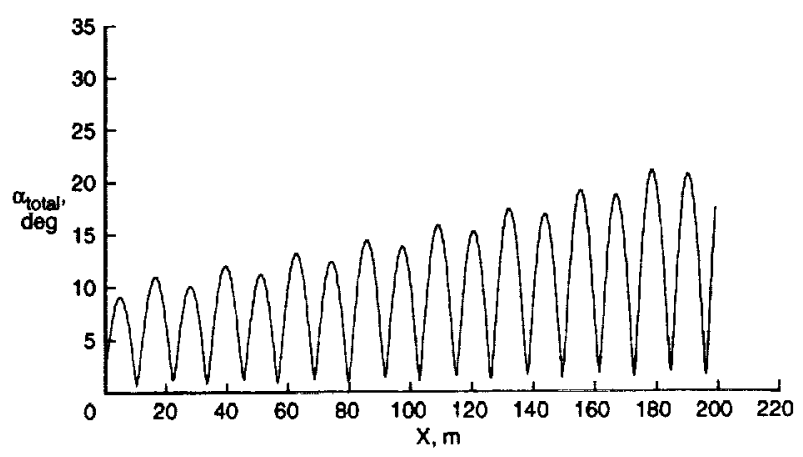

d. Mach 2.6 Average ( $M=3.63$ to 1.48$)$.

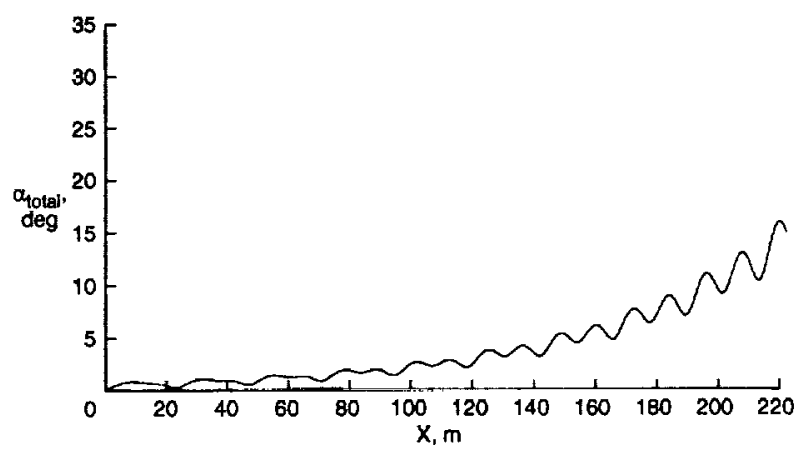

e. Mach 2.8 Average $(M=4.12$ to 1.44$)$.

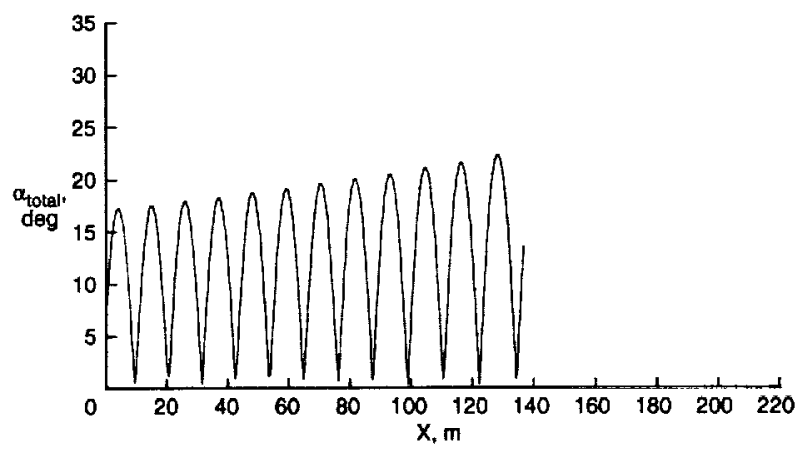

f. Mach 2.9 Average ( $M=3.61$ to 2.10).

Figure 11. Amplitude history for flight tests. 


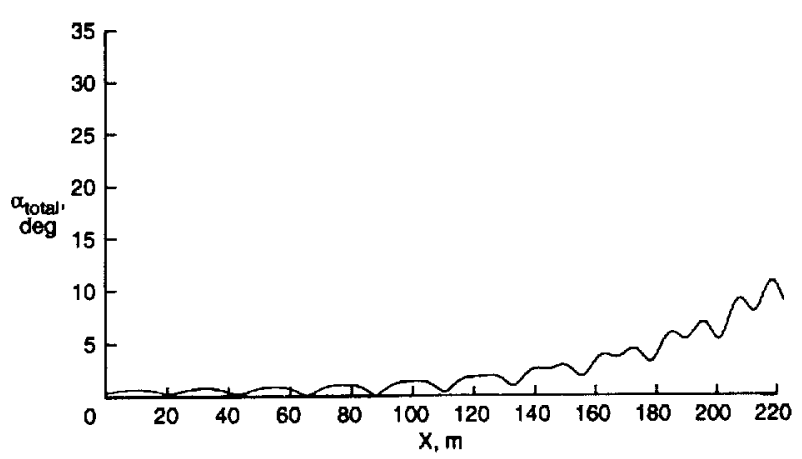

g. Mach 3.0 Average $(M=4.43$ to 1.55$)$.

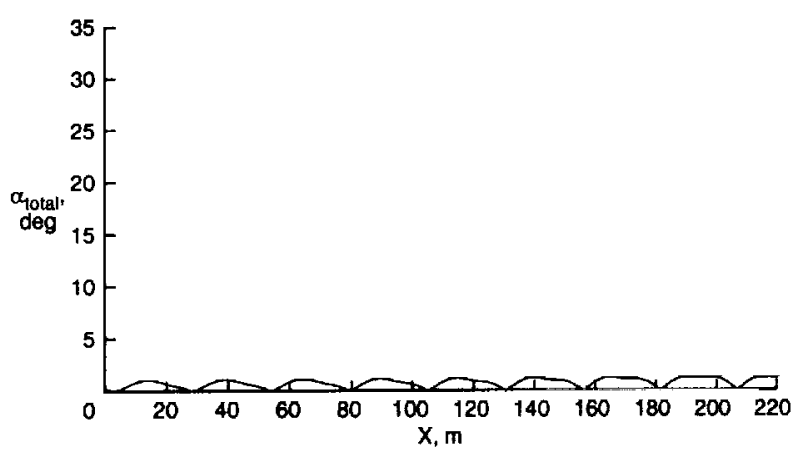

h. Mach 3.0 Average ( $M=4.46$ to 1.58$)$

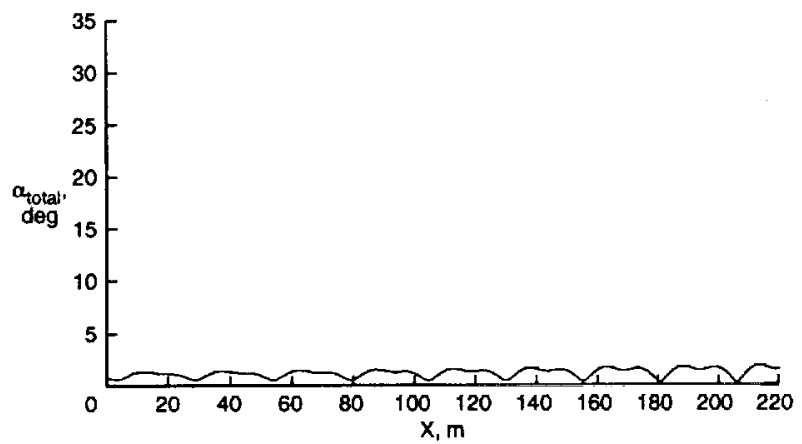

i. Mach 3.1 Average $(M=4.53$ to 1.60$)$.

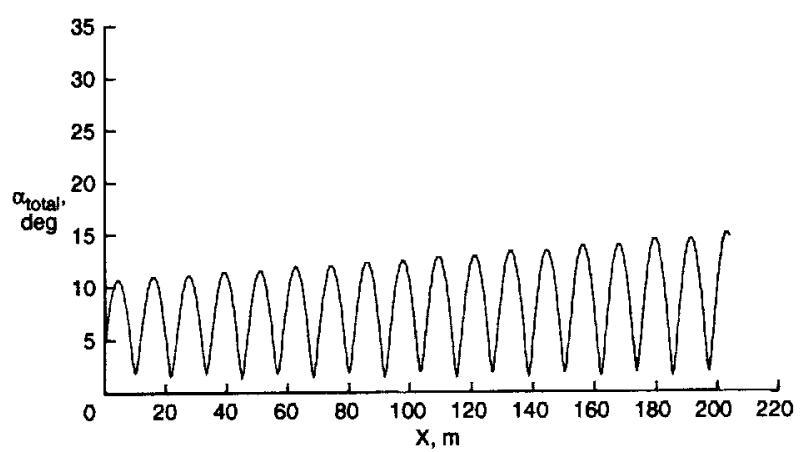

j. Mach 3.1 Average ( $M=4.46$ to 1.77).

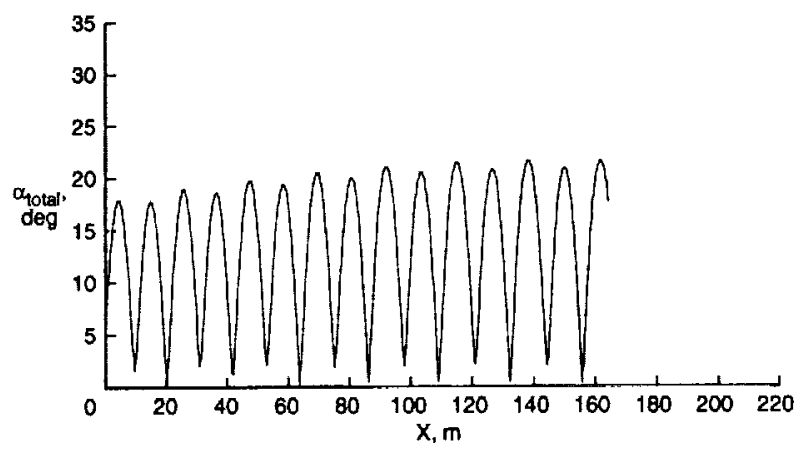

k. Mach 3.3 Average $(M=4.38$ to 2.21).

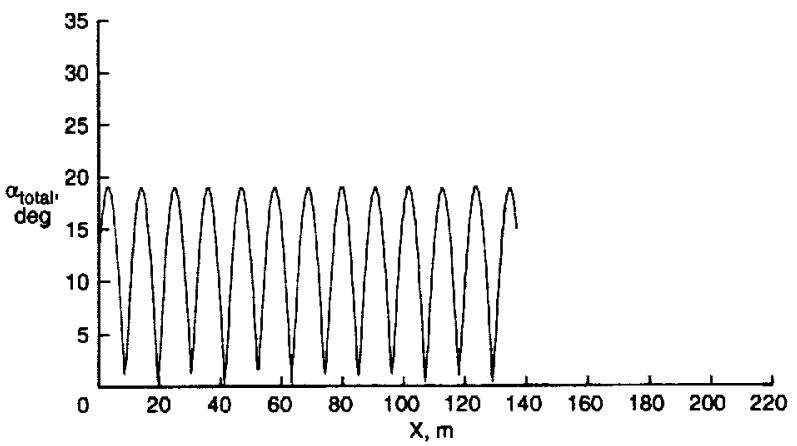

I. Mach 3.5 Average ( $M=4.46$ to 2.60 ).

Figure 11. Concluded.

Although no limit cycles were found experimentally, the aerodynamics for this configuration suggest that potential limit cycles exists. Because the pitch damping is a function of Mach number, there will be a different limit cycle amplitude for each Mach number. The limit cycle amplitude can be estimated using the approach given in Reference 10:

$$
\int_{0}^{\alpha_{\text {totad }}}\left[C_{D}-C_{L_{\alpha}}+\left(C_{m_{q}}\right)\left(\frac{m^{2}}{I_{y}}\right)\right]\left(\frac{d \alpha}{d s}\right) d s=0
$$

This approach assumes that the aerodynamics are independent of Mach number. In the fully dynamic case (with aerodynamics that depend on Mach number), the actual limit cycle amplitude will lag this approximate limit cycle amplitude. 
In general, the terms in the square brackets are a function of angle of attack only. The drag curve and slope of the lift coefficient curve are only weakly dependent on angle of attack and Mach number, and hence, are assumed to be constant. The pitch damping term is a very strong function of angle of attack, and that must be addressed. Therefore, the experimental pitch damping data presented in Figure 10 were fit with a polynomial from 0 to 14 deg angle of attack, and splined to a constant value for angles of attack greater than $14 \mathrm{deg}$. Using this representation, the above equation can be integrated in closed form. The resultant expression is a higher-order polynomial that is solved numerically for the limit cycle amplitude $\left(\alpha_{\text {limit }}\right)$.

The approximate limit cycle amplitude is shown plotted in Figure 12 as a function of Mach number. Here we see that the limit cycle amplitude at the higher Mach numbers near 5 is small (below $5 \mathrm{deg}$ ). The amplitude increases with decreasing Mach number, rising very rapidly below a Mach number of 3.5 . This behavior is consistent with the flight data shown in Figure $1 \mathrm{~g}$ where the Mach number at launch is about 4.5. There we see that the amplitude does not grow very fast until nearly half way down the range (where the Mach number had decreased to about 3 ). It then begins to grow rapidly. These results are also in agreement with the flight shown in Figure 11b, where the launch Mach number is about 2.6 and decreases to near Mach 1. Here the amplitude is growing rapidly to about $35 \mathrm{deg}$ and shows no sign of reducing its growth rate. Since no limit cycle is observed, the vehicle could potentially tumble in a longer flight. The two small angle motions shown in Figures $1 \mathrm{lh}$ and $1 \mathrm{li}$ (at the higher Mach numbers) tend to confirm the very low amplitude limit cycles predicted by the theory.

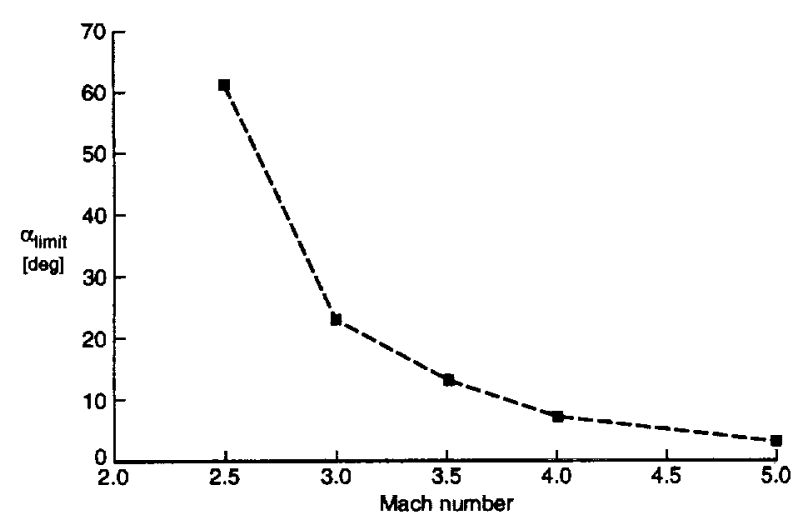

\section{Conclusions}

Aerodynamic force and moment coefficients have been extracted from the measured 6-DoF motions in the AFRL Aeroballistic Research Facility (ARF). The range of Mach numbers covered during these tests was about Mach 1.0 to 4.5. Motion was induced on selected test flights using a launch disturbance method. The database resulting from this test covers a significant range of both Mach numbers and angles of attack.

The pitching moment, normal force, and axial force coefficients vary slightly over this Mach range. The axial force coefficient shows a small nonlinearity as a function of angle of attack, causing $C_{A}$ to decrease with increasing angle of attack. The test results show a pronounced dynamic instability at the lower Mach numbers. No limit cycle below 40 deg was observed for these conditions.

The pitch damping moment nonlinearity (with respect to angle of attack) is the critical parameter in determining the growth rate and magnitude of any existing limit cycle. A comparison of motions at the lower Mach numbers to those at the higher Mach numbers indicates a change in the damping rate. This variation of $\mathrm{Cmq}$ with Mach number and angle of attack was modeled, and the trends presented. The models at the highest Mach numbers, $M>2.5$, apparently are dynamically stable at the higher angles of attack (above $15 \mathrm{deg}$ ).

Changes to the 6-DoF aerodynamic model in ARFDAS were made to include a more general form for the Cmq curve. This expression was then formfactored to best fit the experimental data. This modification to the aerodynamic model provided the angle of attack and Mach number variations required for improved fits to the motion. The theoretical limit cycles were computed across the Mach number range, and are consistent with the experimentally measured motions.

\section{Acknowledgements}

The authors would like to acknowledge Mr. John Krieger, AFRL, for conducting the tests in the ARF; Mr. Werner Esser, German exchange scientist, for designing the sub-scale models; and Dr. Leslie Yates, Aerospace Computing for assisting in reading the film and incorporating updates into the CADRA image processing routine during this program.

Figure 12. Theoretical Limit Cycles. 


\section{References}

${ }^{1}$ Kittyle, R. L., Packard, J. D., and Winchenbach, G.L., "Description and Capabilities of the Aeroballistic Research Facility", AFATL-TR-87-08, Air Force Research Laboratory, Eglin AFB, FL, May 1987.

${ }^{2}$ Winchenbach, G. L., "Aerodynamic Testing In A Free-Flight Spark Range", WL-TR-1997-7006, Wright Laboratory, Eglin AFB, FL, April 1997.

3 Yates, L. A., "A Comprehensive Aerodynamic Data Reduction System For Aeroballistic Ranges", WL-TR-96-7059, Wright Laboratory, Eglin AFB, FL, October 1996.

${ }^{4}$ Fischer, M. A., and Hathaway, W. H., "ARFDAS Users Manual", AFATL-TR-88-48, Air Force Armament Laboratory, Eglin AFB, FL, November 1988.

${ }^{5}$ Murphy, C. H., "Free Flight Motion of Symmetric Missiles", BRL Report 1216, Aberdeen Proving Ground, MD, July 1963.

${ }^{6}$ Murphy, C. H., "Data Reduction for the Free Flight Spark Ranges", BRL Report 900, Aberdeen Proving Ground, MD, February 1954.
${ }^{7}$ Hathaway, W. H. and Whyte, R. H., "Aeroballistic Research Facility Free Flight Data Analysis Using the Maximum Likelihood Method", AFATL-TR-79-98, Air Force Armament Laboratory, Eglin AFB, FL, December 1979.

${ }^{8}$ Sammonds, R., I., "Transonic Static - and Dynamic Stability Characteristics of Two Large - Angle Spherically - Blunted High Drag Cones", AIAA Paper 70-564, Atmospheric Flight Mechanics Conference, Tullahoma, TN, May 1970.

${ }^{9}$ Chapman, G., Berner, C., Hathaway, W., Winchenbach, G., and Mitcheltree, R., "The Use of Spherical Bases to Eliminate Limit Cycles of Blunt Entry Vehicles", AIAA Paper 99-1023, Aerospace Sciences Meeting, Reno, NV, January 1999.

${ }^{10}$ Chapman, G. T. and Yates, L. A. "A Limit Cycle Analysis of Blunt Planetary Probes," AIAA Paper 991022, Aerospace Sciences Meeting, Reno, NV, January 1999. 